\title{
Mucociliary Function: Its Variations with Disease
}

\author{
${ }^{1}$ Hemanth Vamanshankar, ${ }^{2}$ Satish C Kumar, ${ }^{3}$ AP Preetham, ${ }^{4}$ Musarrat Feshan
}

\begin{abstract}
Introduction: This study compares the nasal mucociliary clearance time of patients with chronic sinusitis (pre- and postoperatively) and smokers, with controls, attending the ear, nose, and throat outpatient department at Southern Railway Headquarters Hospital, Perambur, Chennai.
\end{abstract}

Materials and methods: Saccharin granule was used to study mucociliary clearance as it is safe, easy, fast, and reliable. A total of 32 patients in each group were studied. In chronic rhinosinusitis patients, the test was done preoperatively and 4 weeks postoperatively.

Results: The average mucociliary clearance time pre- and postoperatively in chronic rhinosinusitis patients was $29.54 \pm 28.68$ and $12.17 \pm 5.84$ respectively. Cigarette smokers had a longer mucociliary clearance time $(27.63 \pm 21.11)$ compared with beedi smokers $(24.04 \pm 24.93)$. Controls had the fastest mucociliary clearance rate of $9.67 \pm 4.62$ among the study subjects.

Conclusion: Surgery for chronic rhinosinusitis improves both the overall symptoms of chronic rhinosinusitis and the protective functions of the nose and paranasal sinuses. Smokers had an impaired clearance rate compared with normals. As age advances, the mucociliary clearance rate becomes slower.

Keywords: Chronic rhinosinusitis, Mucociliary clearance, Sacchain, Smokers.

How to cite this article: Vamanshankar $\mathrm{H}$, Kumar SC, Preetham AP, Feshan M. Mucociliary Function: Its Variations with Disease. Clin Rhinol An Int J 2016;9(2):68-73.

\section{Source of support: Nil}

Conflict of interest: None

\section{INTRODUCTION}

Mucociliary clearance is a physiological process that allows mucus to flow over an epithelial lamina of ciliated cells and is the first barrier of the nasal fossae and paranasal sinuses against various biological and physical insults. ${ }^{1}$ Several parameters play a role in effective mucociliary clearance: Ciliary beat frequency, rheology of the mucus, and the chemical composition of the mucous layer in which cilia beat. Environmental conditions, such as

\footnotetext{
${ }^{1}$ Senior Resident, ${ }^{2}$ Resident, ${ }^{3,4}$ Senior DMO

${ }^{1-4}$ Department of ENT, Southern Railway Headquarters Hospital Chennai, Tamil Nadu, India

Corresponding Author: Hemanth Vamanshankar, Senior Resident, Department of ENT, Southern Railway Headquarters Hospital, Chennai, Tamil Nadu, India, e-mail: vhemanth2000@ yahoo.com
}

temperature, humidity, and pollution play a role for the mucociliary clearance rates to differ from place to place. ${ }^{2}$

Various methods have been used to evaluate the ciliary activity of the nasal mucosa. Direct methods, such as stroboscopy, roentgenography, and photoelectron techniques, although more reliable, require technology and may not always be available or convenient to use. Indirect methods, such as saccharin test are safe, easy, fast, and reliable studies of mucociliary clearance. ${ }^{3}$

In the saccharin test, the saccharin granule adheres to the nasal mucosa and dissolves. The molecules are then transported as a result of mucociliary function to the nasopharynx, where the sweet taste is recognized by the experimental subject. The time interval between the introduction of the saccharin granule and the sensation of sweetness is measured. ${ }^{4}$

Normal mucociliary time as measured by various studies is between 5 and 15 minutes. $^{5}$

Despite many studies on mucociliary clearance globally, there are not many studies done in the Indian population. Hence, we assessed the impact of mucociliary clearance in chronic sinusitis patients and smokers.

The study compares the nasal mucociliary time of patients with chronic sinusitis (pre- and postoperatively) and smokers, with controls, attending the ear, nose, and throat outpatient department (ENT OPD) at Southern Railway Headquarters Hospital, Perambur, Chennai.

\section{MATERIALS AND METHODS}

This study was conducted in the Department of ENT, Southern Railway Headquarters Hospital, Perambur, Chennai, a tertiary referral care center, between January 2012 and December 2013. In the statistics reviewed, ${ }^{1-3,5-10}$ we found that the sample sizes varied from a minimum of 20 to a maximum of 50 . Hence, we (based on feasibility) studied a total of 32 subjects in each of the groups (chronic rhinosinusitis, smokers, and controls); a total of 96 subjects were studied. Ethical and scientific board clearance was obtained from the hospital for this study. This was a cross-sectional, comparison study.

Patients with suspicion of chronic rhinosinusitis (group I) underwent diagnostic nasal endoscopy, and a computed tomography (CT) scan was done preoperatively. Once diagnosed as chronic rhinosinusitis, these patients underwent endoscopic sinus surgery (ESS) and were on regular follow-up. Patients with previous sinus 
surgeries, malignancy of nose or paranasal sinuses, ciliary disorders, such as immotile cilia syndrome and Kartagener's syndrome, and with general systemic disorders, such as hypertension, diabetes mellitus, and tuberculosis were excluded from this group.

All smokers who presented to the ENT OPD in our hospital formed the second group of patients. Those having symptoms of chronic rhinosinusitis or allergic rhinitis were excluded from this group. History regarding the type of smoking (beedi/cigarette, etc.), the number of pack years, concomitant use of alcohol, or other types of tobacco use, such as tobacco snuffing and gutka was also elicited.

The third group comprised of controls. These included patients walking into the ENT OPD of Railway Headquarters Hospital, Perambur, Chennai, with no symptoms of chronic rhinosinusitis or allergic rhinitis and those who have never smoked in their lifetime.

Patients of all three groups were subjected to a saccharin test. A $5 \mathrm{~mm}$ saccharin granule was placed on the anterior end of the inferior turbinate. The subjects were asked not to sniff, sneeze, smoke, inhale or exhale, eat, or drink during the test. They were asked to swallow every 30 seconds. The time taken by the subject to perceive sweet taste in the throat was taken as the mucociliary clearance time. Subjects who failed to register a sweet taste within 120 minutes were excluded from the study. Patients of chronic sinusitis were evaluated for mucociliary clearance before surgery and 4 weeks after surgery, using the same saccharin test.

The saccharin tablet used in this study was manufactured by Reckitt Benckiser (India) Ltd., by the brand name "Sweetex." Each tablet contains saccharin sodium weighing $13 \mathrm{mg}$. The tablet was broken into half before administering on an individual patient, as most studies in the literature used a 5- to 8-mg tablet, which was adequate to perceive a sweet taste.

Saccharin was used in this study, as it has been used in a lot of previous studies for evaluating mucociliary clearance. It has been proven to be safe, easy, fast, and reliable molecule for testing. Also in the tablet form, it quickly dissolves in the mucosa of the respiratory tract, leaving minimal side effects after its use.

Descriptive and inferential statistical analysis has been carried out in this study. Results on continuous measurements are presented as mean e standard deviation (SD) (Min-Max) and results on categorical measurements are presented as number (\%). Significance is assessed at a $5 \%$ level of significance. The following assumptions on data are made: (1) Dependent variables should be normally distributed, (2) samples drawn from the population should be random, and cases of the samples should be independent.
Analysis of variance has been used to find the significance of study parameters between three or more groups of patients. Student's t-test (two-tailed, independent) has been used to find the significance of study parameters on a continuous scale between two groups (intergroup analysis) on metric parameters.

+Suggestive significance $(0.05<\mathrm{p}<0.10)$

*Moderately significant $(0.01<\mathrm{p} \leq 0.05)$

**Strongly significant $(\mathrm{p} \leq 0.01)$.

\section{Statistical Software}

The statistical software packages, namely Statistical Analysis System 9.2, Statistical Package for the Social Sciences 15.0, Stata 10.1, MedCalc 9.0.1, Systat 12.0, and R environment ver.2.11.1, were used for the analysis of the data.

\section{RESULTS AND DISCUSSION}

Mucociliary clearance can be measured by direct methods, such as stroboscopy, roentgenography, and photoelectron techniques. These, however, require technology that may not always be available or convenient to use in routine studies. Indirect methods, such as the saccharin test or the use of ${ }^{99 \mathrm{~m}} \mathrm{Tc}$ macroaggregated albumin are safe, easy, fast, and reliable studies of mucociliary clearance. ${ }^{3}$

Early studies of mucociliary clearance were based on the movement of dyes or particles deposited on nasal mucosa (Hilding, 1931; Tremble, 1948; Ewert, 1965). Proctor and Wagner (1965) used radioactive microdroplets as a nasal mucous tracer and followed them up with serial scans; this was later modified using single, radioactively tagged resin particles. More recently, Yergin et al have used radiopaque discs of Teflon in the nasal cavity, the movements of which were recorded using a fluoroscopic image intensifier. This study was based on the saccharin particle test first done by Andersen et al in 1974.

The radioisotopic and roentgenographic methods, although direct measures of the mucous transport velocity, cannot be used as screening methods as they require complicated equipment. ${ }^{11}$

\section{Group 1: Chronic Rhinosinusitis Patients}

Bacterial reinfection and self-medicated inflammation caused structural and functional impairment of mucociliary impairment according to Sakakura. ${ }^{5}$ Hardy et al, Golhar (1986), and Wig et al (1988) suggested that although mucociliary activity was quicker in chronic sinusitis of early onset, an inflammatory reaction causing paralysis of cilia and ultimately slow mucociliary transport was noted in the long-standing cases. However, mucociliary clearance time returned to normal in these patients after treatment. It was also noted that mucociliary clearance was delayed 
in chronic rhinosinusitis patients with coexisting deviated nasal septum (DNS) or inferior turbinate hypertrophy. ${ }^{2}$ By contrast, this finding is not present in merely objective pathologies, such as hypertrophic rhinitis or DNS. ${ }^{1}$ Elwany et $\mathrm{al}^{7}$ suggested that the small space between the middle turbinate and the lateral wall of the nose, when exposed to minimal mucosal swelling, can bring opposing mucosal areas into contact, thus impeding their ciliary activity. Increased proteases released by inflammatory mediators contribute to the ciliary damage or loss. Sakakura et $\mathrm{al}^{11}$ suggested that the abundant and sticky mucopurulent secretions of chronic rhinosinusitis patients cause deceleration of particle transport rate and also decrease in the amount of periciliary fluid where cilia beat.

Of the 32 patients of chronic rhinosinusitis in this study, 17 were male (53\%) and 15 (47\%) were female. Nasal obstruction was the presenting symptom in all these patients. Other symptoms included nasal discharge $(50 \%)$, headache $(40 \%)$, sneezing $(34 \%)$, anosmia $(31 \%)$, mouth breathing (19\%), and epistaxis (6\%).

Preoperative CT scans were used to determine the Lund and Mackay staging in these patients: 12 patients $(37.5 \%)$ had a stage $<10 ; 15(46.9 \%)$ had a stage between 10 and 20 , and $5(15.6 \%)$ had a stage $>20$.

Saccharin test was administered in these patients preoperatively and 4 weeks post ESS. The pre- and postoperative values of mucociliary clearance were compared in these patients (Table 1).

None of the patients had any side effects to saccharin preoperatively. However, six patients had side effects of the saccharin test when performed postoperatively. These included nasal irritation (15\%), sneezing (6\%), nasal discharge (3\%), and stuffiness in the nose (3\%).

The mean mucociliary clearance time was impaired irrespective of the duration of the symptoms of rhinosinusitis (Table 2). The average mucociliary clearance

Table 1: Comparative evaluation of mucociliary clearance (Min) pre- and postoperatively in chronic rhinosinusitis patients

\begin{tabular}{lll}
\hline Mucociliary clearance $(\mathrm{min})$ & Preoperatively & Postoperatively \\
\hline Min-Max & $2.30-96.10$ & $3.50-26.35$ \\
Mean \pm SD & $29.54 \pm 28.68$ & $12.17 \pm 5.84$ \\
$95 \%$ confidence interval & $19.19-39.87$ & $10.06-14.27$ \\
\hline
\end{tabular}
$t=3.468 ; p=0.002^{* *}$.

Table 2: Comparison of mean mucociliary clearance ( $\mathrm{min}$ ) according to the duration of chronic rhinosinusitis

\begin{tabular}{llll}
\hline $\begin{array}{l}\text { Chronic } \\
\text { rhinosinusitis }\end{array}$ & $\begin{array}{l}\text { Number } \\
\text { of patients } \\
(n=32)\end{array}$ & $\begin{array}{l}\text { Mucociliary } \\
\text { clearance }(\text { Min) } \\
(\text { mean } \pm S D)\end{array}$ & p-value \\
\hline $\begin{array}{l}\text { Duration (years) } \\
<1.0\end{array}$ & 16 & $28.79 \pm 27.53$ & 0.838 \\
$1.0-5.0$ & 7 & $35.12 \pm 37.02$ & \\
$<5.0$ & 9 & $26.53 \pm 26.43$ & \\
\hline
\end{tabular}

Table 3: Mean mucociliary clearance ( $\min$ ) according to age and gender

\begin{tabular}{clll}
\hline & Controls & Smokers & $\begin{array}{l}\text { Chronic } \\
\text { rhinosinusitis }\end{array}$ \\
\hline $\begin{array}{l}\text { Age in years } \\
\leq 40\end{array}$ & $8.16 \pm 4.10$ & $23.3 \pm 24.47$ & $25.42 \pm 29.39$ \\
$41-60$ & $10.57 \pm 4.36$ & $28.15 \pm 22.91$ & $31.52 \pm 27.50$ \\
$<60$ & $13.80 \pm 6.45$ & $16.20 \pm 6.73$ & $33.98 \pm 37.88$ \\
$\quad \begin{array}{l}\text { p-value } \\
\text { Gender }\end{array}$ & $0.098+$ & 0.485 & 0.821 \\
$\quad$ Male & $10.6 \pm 4.89$ & $23.05 \pm 18.74$ & $23.46 \pm 21.06$ \\
Female & $8.85 \pm 4.35$ & 80.15 & $36.42 \pm 34.9$ \\
$\quad$-value & 0.294 & $0.006^{* *}$ & 0.207 \\
\hline Total & $9.67 \pm 4.62$ & $24.89 \pm 21.09$ & $29.54 \pm 28.68$ \\
\hline
\end{tabular}

Table 4: Comparison of Lund and Mackay CT staging criteria with mucociliary clearance time

\begin{tabular}{lll}
\hline \multirow{2}{*}{$\begin{array}{l}\text { Lund and Mackay } \\
\text { CT staging }\end{array}$} & \multicolumn{2}{c}{ Mucociliary clearance $(\mathrm{min})$} \\
\cline { 2 - 3 } $1-10$ & Number of patients & Mean \pm SD \\
$11-20$ & $12(37.5 \%)$ & $22.65 \pm 17.77$ \\
$<20$ & $5(15.6 \%)$ & $34.02 \pm 34.06$ \\
Total & $32(100.0 \%)$ & $32.60 \pm 34.86$ \\
\hline $\mathrm{F}=0.541 ; \mathrm{p}=0.588$, Pearson correlation $r=0.078 ; \mathrm{p}=0.672$.
\end{tabular}

time preoperatively in chronic rhinosinusitis patients was $29.54 \pm 28.68$, with a minimum clearance time of 2.30 minutes and a maximum clearance time of 96.10 minutes (compared with controls: $9.67 \pm 4.62$ ). Seven patients had a clearance time of greater than 40 minutes (Tables 1 and 3). On comparing the Lund and Mackay CT assessment criteria with the preoperative mucociliary clearance, it was found that more the CT score, the greater was the mucociliary clearance (Table 4).

Postoperatively, the average mucociliary clearance time improved to $12.17 \pm 5.84$, with a minimum clearance time of 3.50 minutes and a maximum clearance time of 26.35 minutes (Table 1). This clearly highlights the role of surgery in chronic rhinosinusitis patients, improving not only their symptoms but also the overall functional capacity of the nose and paranasal sinuses. A review of literature comparing the mucociliary clearance rates of patients with chronic rhiosinusitis is given in Table 5 .

The Lund and Mackay CT staging criteria along with the saccharin test should be recommended in all patients undergoing ESS. Correlating Lund and Mackay's criteria with the saccharin test pre-and postoperatively is a good indicator of the effectiveness of surgery. Both may play a definitive role in the diagnosis and prognosis of chronic rhinosinusitis cases.

\section{Group 2: Smokers and Mucociliary Clearance}

One of the many hazardous effects of cigarette smoking is that it causes impairment in the mucociliary function 
Table 5: Comparison of mucociliary clearance rates of chronic rhinosinusitis patients in literature

\begin{tabular}{lll}
\hline & $\begin{array}{l}\text { Preoperative } \\
\text { mucociliary } \\
\text { clearance time }\end{array}$ & $\begin{array}{l}\text { Postoperative } \\
\text { mucociliary } \\
\text { clearance time }\end{array}$ \\
\hline Pandya et al & $27.2 \pm 11.7$ & - \\
Surinder et al & $10.32 \pm 0.77$ & $7.74 \pm 0.14$ \\
Passali et al & $17 \pm 3$ & - \\
Sakthikumar et al & $16.20 \pm 6.33$ & $10.30 \pm 3.71$ \\
Elwany et al & $37.0 \pm 15.7$ & $20.3 \pm 7.5$ \\
Sakakura et al & $42.0 \pm 38.9$ & - \\
This study & $29.54 \pm 28.68$ & $12.17 \pm 5.84$ \\
\hline
\end{tabular}

of the respiratory tract. ${ }^{5}$ Compounds, such as hydrogen cyanide, acrolein, formaldehyde, ammonia, and phenols in tobacco smoke were found to be toxic to mammalian cilia in vitro and cause ciliostasis to the human respiratory epithelium in vitro. ${ }^{10}$

Tobacco smoke decreases mucociliary clearance mainly by vasoconstriction and enzyme effect. ${ }^{5} \mathrm{Chronic}$ smoking can increase the number of abnormal cilia, which could play a role in the impairment of tracheobronchial clearance. ${ }^{13}$

About $47 \%$ of the smokers in this study were in the age group of 51 to 60 years. However, most of these persons had been smokers for the past 20 to 30 years.

About $53 \%$ of chronic smokers in the study smoked cigarettes, whereas $34 \%$ smoked beedies; $13 \%$ of smokers smoked both cigarettes and beedies. Of these, three patients had stopped smoking in the near past.

This study shows that cigarette smokers had a longer mucociliary clearance time $(27.63 \pm 21.11)$ compared with beedi smokers (24.04 \pm 24.93$)$, although this was not found to be significant (Table 6).

Smokers less than 60 years of age had a longer mucociliary clearance time (Table 3 ).

On analyzing the number of pack years (the number of cigarette/beedi packs smoked per day multiplied by

Table 6: Comparison of mean mucociliary clearance ( $\mathrm{min}$ ) according to the type of smoking, pack years, and alcohol intake in smoking group

\begin{tabular}{llll}
\hline Smoking & $\begin{array}{l}\text { Number } \\
\text { of patients } \\
(n=32)\end{array}$ & $\begin{array}{l}\text { Mucociliary } \\
\text { clearance }(\min ) \\
(\text { mean } \pm S D)\end{array}$ & p-value \\
\hline $\begin{array}{l}\text { Type } \\
\text { Cigarette }\end{array}$ & 17 & $27.63 \pm 21.11$ & 0.637 \\
Beedi & 11 & $24.04 \pm 24.93$ & \\
Both & 4 & $16.31 \pm 2.64$ & \\
Pack years & & & \\
$<100$ & 11 & $19.39 \pm 10.22$ & 0.573 \\
$101-500$ & 14 & $27.66 \pm 22.73$ & \\
$<500$ & 7 & $28.44 \pm 30.49$ & \\
Alcohol intake & & & \\
No & 14 & $28.36 \pm 26.59$ & 0.416 \\
\hline
\end{tabular}

the number of years of lifetime smoking), we found the majority to be within 500 pack years. Seven persons were found to have more than 500 pack years. As the number of pack years increased, so did the mucociliary clearance time (<100: $19.39 \pm 10.22$; 101-500: $27.66 \pm 22.73$; $>500: 28.44 \pm 30.49$ ).

Smokers were also asked about the concomitant use of alcohol. We found that 18 of these patients also consumed alcohol, among which $31 \%$ had been consuming alcohol for more than 20 years in their life. Based on the alcohol consumption per week, persons were further classified as being light, moderate, excessive, and very excessive drinkers $^{12}$ (Table 7). Eight persons were light drinkers, five were moderate, four were excessive, and one was a very excessive drinker. Persons concomitantly consuming alcohol did not show an overall increase in the mucociliary clearance rate $(22.05 \pm 15.49)$ compared with only smokers $(28.36 \pm 26.59)$.

Among the smokers, three persons also gave a history of using tobacco snuff and four persons gave a history of chewing betel nut.

Side effects to saccharin tablet were observed in 10 persons (32\%). These included nasal irritation in two patients, pain/burning sensation in two patients, and sneezing in one patient.

The average mucociliary clearance in smokers using the saccharin test was found to be $24.89 \pm 21.08$, which was much higher than that in controls $(9.67 \pm 4.62)$ (Table 8). This was statistically significant and clearly proves that smoking cigarettes/beedies with or without concomitant alcohol intake has a detrimental value with

Table 7: Alcohol consumption index, adapted from Garretsen ${ }^{12}$

\begin{tabular}{|c|c|c|c|c|}
\hline \multirow[t]{2}{*}{$\begin{array}{l}\text { Number of days of } \\
\text { drinking alcohol }\end{array}$} & \multicolumn{4}{|c|}{$\begin{array}{l}\text { Number of alcohol consumptions } \\
\text { each time }\end{array}$} \\
\hline & 6 or more & $4-5$ & $2-3$ & $0-1$ \\
\hline 5-7 days per week & $\begin{array}{l}\text { Very } \\
\text { excessive }\end{array}$ & Excessive & Moderate & Light \\
\hline 3-4 days per week & Excessive & Moderate & Moderate & Light \\
\hline $1-2$ days per week & Excessive & Moderate & Light & Light \\
\hline $1-3$ days per month & Moderate & Light & Light & Light \\
\hline$<1$ day per month & Light & Light & Light & Light \\
\hline
\end{tabular}

Table 8: Comparison of mucociliary clearance (min) in three groups studied

\begin{tabular}{llll}
\hline $\begin{array}{l}\text { Mucociliary } \\
\text { clearance time } \\
(\mathrm{min})\end{array}$ & $\begin{array}{l}\text { Controls } \\
(n=32)\end{array}$ & $\begin{array}{l}\text { Smokers } \\
(n=32)\end{array}$ & $\begin{array}{l}\text { Chronic } \\
\text { rhinosinusitis } \\
(n=32)\end{array}$ \\
\hline $1-10$ & $17(53.1 \%)$ & $3(9.4 \%)$ & $7(21.9 \%)$ \\
$11-20$ & $13(40.6 \%)$ & $15(46.9 \%)$ & $11(34.4 \%)$ \\
$21-30$ & $2(6.3 \%)$ & $6(18.8 \%)$ & $4(12.5 \%)$ \\
$31-40$ & $0(0 \%)$ & $3(9.4 \%)$ & $3(9.4 \%)$ \\
$<40$ & $0(0 \%)$ & $5(15.6 \%)$ & $7(21.9 \%)$ \\
Mean \pm SD & $9.67 \pm 4.62$ & $24.89 \pm 21.08$ & $29.53 \pm 28.67$ \\
\hline $\mathrm{F}=9.718 ; p<0.001^{\text {** }}$ & &
\end{tabular}


Table 9: Comparison of mucociliary clearance rates among smokers in literature

\begin{tabular}{llll}
\hline Pandya et al & Stanley et al & Proenca et al & This study \\
\hline $30.4 \pm 11.1$ & 22.2 & $16 \pm 6$ & $24.89 \pm 21.08$ \\
\hline
\end{tabular}

regard to mucociliary clearance. Chronic smoking may also cause an increased susceptibility of such a person to develop infections in the nose, especially chronic rhinosinusitis, due to loss of the protective role of mucociliary clearance.

Table 9 compares studies showing mucociliary clearance rates among smokers with other studies done previously.

\section{Group 3: Controls}

Among the controls, 17 were female (53\%) and 15 were male $(47 \%)$. Females had a slightly faster rate of mucociliary clearance $(8.85 \pm 4.35)$ compared with males $10.6 \pm 4.89$ ) (Table 3).

It was noted that as age advances, the mucociliary clearance time also increases. It was longest in patients $>60$ years $(13.80 \pm 6.45)$ (Table 3$)$. This finding was statistically significant and could possibly mean that as age advances, there is a decrease in the number of cilia or a decline in the ciliary beat frequency.

On administration of saccharin to this group, 25\% (eight patients) were found to have side effects to saccharin. These included nasal irritation (four), nasal stuffiness (three), nasal discharge (two), pain/burning sensation in the nose (two), sneezing (one), and lacrimation (one).

The average mucociliary clearance time noted in this group was $9.67 \pm 4.62$, which was the least compared with the other two groups (Table 8). Table 10 gives a literature

Table 10: Comparison of mucociliary clearance rates among controls in literature

\begin{tabular}{ll}
\hline Name of the authors & $\begin{array}{l}\text { Mucociliary clearance rates } \\
\text { among normals/controls }\end{array}$ \\
\hline Pandya et al & $9.5 \pm 6.1$ \\
Surinder et al & $6.99 \pm 0.26$ \\
Elwany et al & $12.8 \pm 7.9$ \\
Puchelle et al & $18.6 \pm 6.5$ \\
Sakakura et al & $14.6 \pm 9.8$ \\
Stanlet et al & 11.1 \\
Yadav et al & $8.21 \pm 0.25$ \\
Proenca et al & $10 \pm 4$ \\
Anderson et al & $12-15$ \\
Birch and Elbrnd & 10 \\
Mackay et al & $12.2-14.8$ \\
Passali et al & $9.6-15.4$ \\
Shashi Chetan & $8-19$ \\
This study & $9.67 \pm 4.62$ \\
\hline
\end{tabular}

review, comparing the mucociliary clearance rates of controls in various studies.

About 20 to $30 \%$ persons of each of the three groups consistently had side effects to saccharin. Among the side effects noted, chronic rhinosinusitis patients mostly had symptoms of nasal irritation; smokers had equal incidences of irritation and pain/burning sensation in the nose. In controls, symptoms varied from irritation, discharge, sneezing, stuffiness, and pain/burning sensation.

\section{CONCLUSION}

The study was conducted on a total of 96 patients (32 each of chronic rhinosinusitis patients, smokers, and controls). Saccharin test was used to evaluate the mucociliary clearance on all these patients.

The mucociliary clearance rates in patients with chronic rhinosinusitis improved postendoscopic surgery, proving surgery to be beneficial in this group of patients. The saccharin test for mucociliary function should be recommended in all cases of ESS, pre- and postoperatively, to test the functional efficacy of surgery. Correlation of the Lund and Mackay CT staging criteria with the saccharin test, pre- and postoperatively, should be recommended for functional assessment of surgical outcome.

Smokers overall had an impaired clearance rate, but it was worse in cigarette smokers compared with beedi smokers. Concomitant alcohol use in smokers did not increase the overall mucociliary clearance rate compared with only smokers.

As age advances, the mucociliary clearance rates tend to be longer, as observed among controls in this study. Controls had an overall faster clearance rate compared with other groups in the study.

\section{REFERENCES}

1. Passali D, Ferri R, Becchini G, Passali GC, Bellussi L. Alterations of nasal mucociliary transport in patients with hypertrophy of the inferior turbinates, deviations of the nasal septum and chronic sinusitis. Eur Arch Otorhinolaryngol 1999;256(7):335-337.

2. Surinder MB, Sunder S, Ajit S. Mucociliary clearance in chronic sinusitis. Indian J Otolaryngol Head Neck Surg 1998 Jan;50(1):15-19.

3. Naxakis S, Athanasopoulos I, Vlastos IM, Giannakenas C, Vassilakos P, Goumas P. Evaluation of nasal mucociliary clearance after medical or surgical treatment of chronic rhinosinusitis. Eur Arch Otorhinolaryngol 2009 Sep;266(9): 1423-1426.

4. Asai K, Haruna S, Otori N, Yanagi K, Fukami M, Moriyama H. Saccharin test of maxillary sinus mucociliary function after endoscopic sinus surgery. Laryngoscope 2000 Jan;110(1): 117-122.

5. Pandya VK, Tiwari RS. Nasal mucociliary clearance in health and disease. Indian J Otolaryngol Head Neck Surg 2006 Oct;58(4):332-334. 
6. Puchelle E, Aug F, Pham QT, Bertrand A. Comparison of three methods for measuring nasal mucociliary clearance in man. Acta Otolaryngol 1981 Mar-Apr;91(3-4):297-303.

7. Elwany S, Hisham M, Gamaee R. The effect of endoscopic sinus surgery on mucociliary clearance in patients with chronic sinusitis. Eur Arch Otorhinolaryngol 1998;255(10):511-514.

8. Sakthikumar KR, Ravikumar A, Mohanty S, Senthil K, Somu L, Kuruvilla S. Functional study of nasal mucosa in endoscopic sinus surgery and its correlation to electron microscopy of cilia. Indian J Otolaryngol Head Neck Surg 2008 Mar;60(1):1-6.

9. Yadav J, Verma A, Singh J. Study on nasal mucous clearance in patients of perennial allergic rhinitis. Indian J Allergy Asthma Immunol 2003;17(2):89-91.
10. Stanley PJ, Wilson R, Greenstone MA, MacWilliam L, Cole PJ. Effect of cigarette smoking on nasal mucociliary clearance and ciliary beat frequency. Thorax 1986 Jul;41(7):519-523.

11. Sakakura Y, Ukai K, Majima Y, Murai S, Harada T, Miyoshi Y. Nasal mucociliary clearance under various conditions. Acta Otolaryngol 1983 Jul-Aug;96(1-2):167-173.

12. Garretsen, HFL. Probleemdrinken: Prevalentiebepaling, beinvloedende factoren en preventiemogelijkheden: Theoretische overwegingen en onderzoek in Rotterdam. Lisse: Swets \& Zeitlinger; 1983 (in Dutch).

13. Bousquet J, Van Cauwenberge P, Khaltaev N; Aria Workshop group; World Health Organization. Allergic rhinitis and its impact on asthma. J Allergy Clin Immunol 2001 Nov;108(5):S147-S334. 